\section{Cancer: The Evolutionary Legacy}

\author{
By Mel Greaves \\ Oxford University Press, \$27.50, 240 pp. \\ ISBN 0192628356, 2000
}

Reviewed by C. Michael Steel

Professor of Medical Science

University of St Andrews

School of Biology

St Andrews

Fife, KY16 9TS, UK

Email:cms4@st-and.ac.uk

Why does press reporting of cancer issues make you cringe? Why are misconceptions about the nature and the causes of cancer so widespread? Why are totally unsupported approaches to treatment given currency even by intelligent people? Because Mel Greaves' book was not written earlier. Why not? I do not know.

Cancer: the Evolutionary Legacy is promoted as the first book to put cancer in its evolutionary framework, and in his preface Mel Greaves makes much of the demystifying power of a Darwinian perspective. In fact, his approach is conventional rather than radical and based on straightforward cell biology. What is distinctly unconventional is his presentation. His declared intention is "to draw a multi-dimensional and dynamic picture in which essential details highlight principles rather than obfuscate." To achieve that, he adopts the role of scientist as barrister, supporting coherent argument with a wealth of anecdotal and circumstantial evidence rather than dwelling on experimental details that might amount to formal proof but would be a turn-off to a general readership.

The chapters are short, grouped into a series of themes, and supplemented, in a non-distracting manner, by references and short notes at the end of each group. The style is first-person conversational, and Greaves has no compunctions about letting his own excitement show. At times, the prose becomes quite breathless, but equilibrium is quickly regained and all essential points are covered more than once, from varying perspectives, so that the reader is unlikely to feel bemused for long.

There is no talking down to the audience. Greaves uses technical language where it is appropriate, explaining and illustrating their meanings in down-to- earth terms. Cells "snuff it," FISH provides a "molecular mug shot" and "we're back on the p53 bus again." He is also partial to extravagant figures of speech, which can raise a smile but can also be wonderfully apt: "The ancient Babylonian and Greek thesis of the universality of the four elements (air, water, fire and earth) and their analogous humours in the body (blood, phlegm, yellow bile and black bile) proved a mental gridlock."

The first section of the book gives a historical perspective on cancer. It is followed by a racy account of basic cell-population dynamics and the sequential accumulation of mutations in genes that regulate cell growth and behavior. Section three deals with environmental factors in carcinogenesis, and the final chapter covers therapeutic successes, failures and prospects. Although the 'meat' is in the two central sections, the unifying theme of the fundamental nature of cancer is in clear focus from start to finish. Greaves' own mastery of the field allows him to take entertaining diversions and to draw his illustrations from unexpected sources without losing the thread of his argument. I would disagree with his perception that the expression of telomerase in germ cells constitutes "a problem" for an evolutionary perspective on cell biology, and I suspect that he has inadvertently entangled juvenile polyposis with ulcerative colitis, but such nit-picking is out of place in assessing a book that has the overwhelming merits of combining sound science with readability. The word 'entertaining' might seem out of place in the context of cancer, but Greaves manages to be just that without insensitivity, and the book can safely be recommended to the many cancer patients who want to know more about the background to their diagnosis.

The target audience is clearly the intelligent layman (of both genders), among whom, it is to be hoped, journalists and other opinion-formers may be included. If the book is as widely read as it deserves to be, we could see a dramatic reduction in junk articles and a corresponding improvement in the level of public debate on cancer-related issues. These have always been matters of general fascination, but the gulf between scientist and public has been immense. Mel Greaves has performed a huge service in writing a book that is both accurate and accessible. It should be piled high in supermarkets and distributed, at taxpayers' expense, with packs of cigarettes.

\title{
Still waiting for the revolution
}

In May 1999, the National Institutes of Health (NIH) announced an ambitious plan for an electronic repository of both peer-reviewed and unreviewed biomedical research papers, which would be available in full and cost-free on the web. This sparked a furious debate amongst librarians, scientists and publishers, which raged for most of 1999.

PubMed Central (PMC) (http://www.pubmedcentral.nih.gov/index.html), as it came to be known, was officially launched in February. So what has become of proposed revolution in scientific publishing? The answer would seem to be: not much. PMC promised free access to the contents of Molecular Biology of the Cell (two months after publication) and to the Proceedings of the National Academy of Sciences (PNAS; delayed by four weeks). However, the site has remained depressingly static since its launch. The November 1999 issue of Molecular Biology of the Cell is freely available, but monthly updates have not yet appeared. The promised PNAS content is completely absent, and contributions from such journals as the Biochemical Journal and the Canadian Medical Association Journal remain a pipe dream.

The internet moves forward with incredible speed and waits for no one; it also has no respect for reputation-even that of the prestigious $\mathrm{NIH}$. And while the developers of PMC fiddle, other electronic publishers have made progress: HighWire Press (http://www.highwire.org) announced in March that they intend to grant free access to the back issues of 83 of their electronic journals-over 137,000 articles.

If PMC represents the internet revolution for scientific publishing, my advice is: Don't cancel your print subscription just yet.

John MacFarlane, Web Editor, Nature 